\title{
E-Tools and the Globalised World of Learning and Communication
}

\author{
Juliet Stoltenkamp \\ Jephias Mapuva \\ University of the Western Cape, South Africa
}

\begin{abstract}
The utilization of the knowledge economy in the information age has been promoted by various tools developed both for communication and marketing purposes. Information and communication technologies (ICTs) have proved their propensity to influence the flow, acquisition and dissemination of information across the globe. The business and education sectors have been the most conspicuous of all beneficiaries of ICT applications, especially in the fast-globalizing environment where interaction has become a necessity and an obligation rather than leisure. Enhanced tools for education, marketing and communication purposes have been coined with unprecedented efficacy and efficiency. Some of these technologies (e.g. blogs) have even livened communication and interaction among users. This paper will therefore focus on various e-tools and their application to open education, with prevalence being on the blog tool.
\end{abstract}

Key words: E-tools; Globalized education; E-learning; Communication; Technology; Blogs

\section{Introduction}

As the pace of changes in educational technology continues unabated, it is essential to reflect on those transferable principles of our practice that will be of benefit to others. The implications of elearning are that learning and teaching have been moved to the desktop, where teaching and learning can take place in self-paced (asynchronous) formats or in virtual classes through the use of synchronous tools. As e-learning technologies have become more advanced, learning can be customized automatically based on an initial assessment of learner needs. Some experts also see the evolution of learning content toward shorter learning chunks. Technologies that enable threaded discussion groups, chat rooms, synchronous meeting tools, and other collaborative software are among technologies being adopted in e-learning settings. More advanced tools, such as knowledge databases that archive unstructured knowledge resources in ways that can quickly be searched through keyword, form the next step in developing e-learning. E-learning emerges from the current needs of the knowledge-based society. Basic requirements for knowledge-ondemand learning are presented: anyone, anytime, anywhere delivery of education and training, adapted to the specific requirements and preferences of each individual citizen within different elearning settings (Wong, 2003).

The introduction and vital role that ICTs have played across the globe in attempting to connect different people/spaces have reached unprecedented levels and will be discussed in this article. In 
the education sector, appropriate pedagogical approaches had to be coined in tandem with changing technological innovations as demanded by the increasing demand for higher education opportunities and an influx of students have continuously sought to improve their skills. All these exerted much pressure on technology demands to deliver and to come up with more efficient methods and approaches to information dissemination and approaches that are not only userfriendly, but convenient for students, both full time and part-time. This is where online distance education has stolen the limelight as the best option to reach out to students and to defeat the challenges poised on students who have work commitments or impeded by distance for the institution of learning. This is where technology has come in handy as without technology, no meaningful communication between students and their lecturers would be realized. This article will also deliberate on cutting-edge communication and marketing e-tools such as blogs, twitter, chat-rooms, and discussion forums as well as various social utilities that help to the whole learning process as integral part of communication.

\section{Globalization and ICTs}

Co-existence between and among different people with different needs and desires has necessitated the need for interaction, especially in an environment where people have found themselves among different cultures and personalities. The need for efficient communication tools has also been necessitated by globalization.

The process of globalization has encouraged closer economic, political and social interaction. This in turn necessitated the activation of multiplicity of levels of analysis in the fields of economics, politics, society and culture. In most basic terms, the globalization of the world economy is the integration of economies throughout the world through trade, financial flows, the exchange of technology and information, and the movement of people (IMF, 1997).

Globalization is characterized by the fact that distance and national borders no longer matter, the ease with which business with a customer across the globe can take place and that the nation state and geography are no longer relevant for economic purposes. While the opportunities and benefits of the opening of economies are emphasized by its proponents and supporters, disillusionment is growing among many policy-makers and economists about the costs and risks involved in the globalization of national economies as well as the impact of it on future growth prospects.

In the context of globalization and knowledge economies, higher education in its knowledge producing and disseminating function, is recognized as an essential driving force for national development in both developed and developing countries. At the same time, in its universality and international dimensions, higher education can be seen as both an actor and reactor to the phenomenon of globalization.

World Bank has been quick to provide a general definition which addresses the dynamic (and unpredictable) economic trends of the $21^{\text {st }}$ by noting that, "in recent years a quickly rising share of economic activity in the world seems to be taking place between people who live in different countries" (cited in Wells, 2004). Harris's (1993) is more specific with reference to economic 
globalization which he cites as "the increasing internationalization of the production, distribution and marketing of goods and services" (p.755).

Despite the seemingly divergent views on what globalization entails, a cord has been struck by different scholars who have concurred that the driving forces behind economic globalization are:

- A reduction in transport and communication costs in the private sector.

- Reduced policy barriers to trade and investment by the public sector.

- An increase in the availability of and access to information and technology.

- The speed with which information and technology can be transmitted across national boundaries (Frankel, 2000; Rodrik, 1997).

\section{Globalization and the Communication Discourse}

Proponents of the use of technology for communication argue that "... ICTs are creating a new world, an interactive, truly democratic world" (Rushkoff, 1997). The central argument for these proponents is that ICTs are able to enhance interactivity among people thereby inflicting an element of freedom of expression, which they mean by being able to create a "truly democratic world." The notion of communication is not as abstract as the market. Because persons are bound together through communication, a community of traders is possible to imagine. This article deliberates on the role of enhanced communication in an environment that has succumbed to globalization. Increased travels around the world and the unprecedented need for exchange of information for business and through social utilities like the blog and face book has seen an increased need to pass information through to other people irrespective of the distance involved. This has incidentally brought the concept of globalization and its precincts to the fore. Increasing globalization tendencies being adopted across the globe have dictated the need for enhanced communication strategies which would enable actors across the globe to interact and exchange information.

How does e-learning impact on communication in an increasingly globalizing world of learning and teaching?

The term e-learning is ambiguous to those outside the e-learning industry, and even within its diverse disciplines it has different meanings to different people. For instance in companies, it often refers to the strategies that use the company network to deliver training courses to employees and lately in most universities, e-learning is used to define a specific mode to attend a course or programs of study where the students rarely or never meet face-to-face, nor access on-campus educational facilities, because they study online (en.wikipedia.org/wiki/Online_education).

E-Learning is often heralded as the magic agent who will allow schools and other educational institutions to transform and re-engineer the learning process by reaching "the parts (of our students' cognitive processes) which other forms of learning can't". E-Learning refers to the ability to acquire information, knowledge and skills through the use of multimedia technologies and the Internet. 
The impact of telecommunication boom on education has become inevitable in recent times. The unprecedented developments in information and communication technologies (ICTs) are linked and commensurate with other significant social and economic changes. This has resulted in a higher demand for education and training in response to the ever increasing list of challenges of emerging "knowledge economy" and "knowledge society" in an attempt to come up with a digitally-literate citizen who is able to learn and take responsibilities for continuous personal learning development and employability (The European E-Learning Summit Task Force, 2001). This is how distance education has come to represent a mode of learning and communication where the learner does not need to travel long distances in quest of class attendance. This can only be effective when the appropriate infrastructure, resources and efficient ICT apparatus are in place to facilitate an effective communication channels with students. E-Learning has become handy in such scenarios where the tutor and the learner have got to interact using technology. This is the principal essence behind e-learning and its impact on education has been unprecedented.

With the advent of globalization, there has been a dire need and urge among people to improve their skills on the face of an increasingly competitive job market and general environment, resulting in many enrolling for courses as a way of skills development on the backdrop of economies where the same people had to balance between work and learning.

The dilemma however has been with how best these people could simultaneously work and learn. The most suitable option for many has been to enroll for distance education courses where technology would facilitate communication with their respective institutions and be able to get feedback at the same time. This has also benefited companies which have been able to gain from their increased skills base compounded by higher education institutions which have been able to procure appropriate technologies for teaching and learning purposes. The co-existence of the private (companies) and public (educational institutions) sectors has further been cemented as these two sectors have realized how interdependent they really are.

For cyber-enthusiasts, the new information and communication technologies increase our choices. They argue that given the myriad of technologies in existence (and many of them being easily accessible) cyber-enthusiasts maintain that it is a matter of choice from available alternatives of technologies and technological configurations. The same lee-way for choices is available to those seeking to improve their skills through enrolling for tertiary courses. For those attending full time classes state-of-the-art technologies have enhanced their comprehension of concepts as the use of such communication tools as the blog, chat-rooms, discussion forums, wikis as well as the more exiting gadget such as the podcasts has generated much interest among the student population, thereby making learning and teaching more of a luxurious pursuit that the monotonous task that it would have been without these technologies. Chat-rooms, discussion forums and e-conferencing have provided for a platform where interactional activity is enhanced and promoted while at the same time people share ideas and be able to give their point of view on a number of issues and topics.

Inherently, proponents of cyberspace further note that ICTs have the potential to be egalitarian, to bring everyone into a network arrangement. It has the capacity to create community; to provide untold opportunities for communication, exchange and keeping in touch. Given these precincts from proponents of ICTs as a mode and medium of communication, it is becoming evident that 
technologies have the propensity to transform the world into a seamless and borderless community of nations where reachability becomes a norm.

\section{Enhancing Communication in the Information Age}

The Information Age, also commonly known as the Computer Age or Information Era, is an idea that the current age will be characterized by the ability of individuals to transfer information freely, and to have instant access to knowledge that would have been difficult or impossible to find previously. The idea is also linked to the concept of a Digital Age or Digital Revolution, and carries the ramifications of a shift from traditional industry that the Industrial Revolution brought through industrialization, to an economy based around the effective manipulation of information (Wikipedia, 2009).

Communication in the Information Age has been modeled by the type of communication tools in use. As the need for communication between and among different people living in faraway places continued to grow, so has been the desire to invent more efficient communication tools. As a response to the dire need for reaching out to people across the globe in a very short space of time, users and ICT experts have continuously come up with more sophisticated communication tools, with the blog and twitter being among the latest in a continuously changing range to e-tools.

In the context of online education, two types of communication can be identified: synchronous and asynchronous. Synchronous communication requires participants to interact at the same time (Bates, 2005; Bates \& Poole, 2003). Examples are a live one-way broadcast of a lecture and live two-way interaction among a number of students and instructors (as in an online tutorial). Asynchronous communication does not require the interacting participants to be present at the same time; discussion forums and emails can be used. In their meta-analysis, Zhoa et al. (2004) examined the effects of type of communication in distance courses. They found that courses incorporating both synchronous and asynchronous means of communication were more effective than courses featuring only one type.

The effect of communication type may differ according to the intended outcome. Allen et al. (2003) suggest that the type of communication used in a distance course may influence satisfaction of students. Even if communication type was unimportant in terms of students' grades, it may still be important because student satisfaction is a major factor predicting drop-out and retention (Allen et al. 2003). For instance, Bullen (1998) found that students appreciated having access to other students' ideas and comments in online discussion, and reported that this had a positive impact on their involvement in a unit.

\section{Identification of Marketing Communication Tools}

Technological innovations have realized benefits for commerce, industry and education. In the education sector e-tools have been used to enhance communication, which through globalization, have been made easy for interaction to be executed at a very fast rate. Marshall, Kinuthia, and Taylor (2009) have noted that educational technology can utilize ICT to transform education and 
assist developing communities to close the knowledge divide, especially through the utilization of e-tools. Chat-rooms, discussion forums, wikis and blogs have been some of the predominantly used communication tools. This article is going to explore debates around blogs and blogging as well as how these have enhanced communication and marketing of e-learning.

Research has established the above cited e-tools have enhanced communication and opened up further communication channels between and among individuals and institutions. The tools have also been used to establish the extent to which this communication tool has been utilized to facilitate communication between various parties within the institutional setting, as well as a marketing tool to expose e-learning practices within the institution, thereby attracting staff to adopt e-tools to supplement their teaching and learning practices. This will facilitate a paradigm shift towards the use of, and in preference to e-learning as a supplementary mode to the traditional talk-and-chalk teaching method.

For this article the communication and interaction is between the e-learning team and various academic and institutional leadership with the objective of attempting to determine the extent to which they have benefited from e-learning facilities at their disposal, as well as the effectiveness and impact of e-learning as a supplement to the traditional mode of educational instruction. However, due to limited space, the article is not going to deliberate on all the mentioned communication tools. Accordingly, only the blog is going to form the case study to establish to what extent and with what results the blog has facilitated interaction within the institution. Despite the fact that all the cited utilities are in use at the institution, the authors have decided to provide an insight into the effectiveness on the blog, especially given the active interaction and engagement that has materialized between the e-learning Division which is driving the e-learning initiative in the institution and academics who are the clients and users of the learning facility to teach students.

\section{E-Pedagogy and Communication Tools}

In the communication discourse, pedagogy facilitates communication between the learner and the tutor because it is all about the methodology of what method the tutor uses to disseminate information to learners. The ever rising prominence of technological innovations has made educationists to explore the possibility of employing social utilities for educational purposes and research has revealed that that produced impressive results. Using ICTs for educational purposes does not only yield good results, but adds excitement to learning and makes the tutor's work less laborious. Subsequently cyber-enthusiasts have been able to make use of e-tools to reach out to learners and other people whose quest for education could not be met through conventional means. As a result, all communication e-tools cited above can be utilized for educational purposes.

Existing trends in the field of distance education have indicated a paradigm shift in pedagogical perspectives and theoretical frameworks, with student interaction at the heart of learner-centered constructivist environments. Among technologies that have highlighted trends in modern technologies include e-tools such as wikis, blogs and podcasts. Research on the impartation of emerging technologies have explored the benefits of using emerging technology tools such as wikis, blogs, and podcasts to foster student interaction in online learning. Although emerging 
technologies offer a vast range of opportunities for promoting collaboration in both synchronous and asynchronous learning environments, distance education courses and around the globe have encountered challenged that may limit or deter implementation of these technologies.

Endeavoring to address problems and ensure student access to course material, university lecturers have availed of recent technological developments and podcast lectures. Being able to download podcast lectures and listen to them at a convenient time and place would seem to be an ideal solution for 'time-poor' students and is often cited as a major reason for university lecturers to consider podcasting their lectures. Furthermore, there is evidence that students consider podcasting lectures as being of 'excellent value' to them in their studies (Tynan \& Colbran, 2006). While students may consider podcasts to be 'excellent value' from an intrinsic convenience perspective, a more critical concern is how students utilize podcast lectures and how this is associated with students' academic performance. Convenience is important for time-poor students, but can podcasts be used as a substitute for lecture attendance, or are they more useful as revision tool. At the University of the Western Cape, the inception of e-learning and its sister portal e-teaching have provided an opportunity for academic staff and students to be exposed to technology and apply it to teaching. Although a number of e-tools have been in use, emphasis has been placed on blogs, given its prominence within the institution.

\section{Citing the Blog as an Effective Communication E-Tool}

Globalization has made the use of enhanced communication tools mandatory. The situation has further been exacerbated by the advent of ICTs which have taken communication to dizzy heights, thereby making it necessary for people across the globe as well as in institutions to be able to interact anytime anywhere. The dynamic nature of technology has transformed the face of communication. New, efficient and enhanced communications tools, such as blogs, have come to supersede the previously glorified Internet technology which had, over the years, dominated the communication discourse. Through blogs and blogging, interaction has been enhanced and livened. News and information have been able to be exchanged and disseminated throughout the world in a short space of time. Interaction has become more exciting, as bloggers and viewers have been able to interact and provide comments. Research findings can be posted by bloggers on their websites for access by other researchers and users of the website.

Given the dynamics of globalization, Internet has been able to buttress the use of e-tools such as blogs and other communication tools that are on offer. Through blogging and blogs, various departments and staff have been able to interact on pertinent issues, especially the usability and efficiency of blogs and e-tools within the University of the Western Cape. This article further seeks to share how an e-learning support unit at the institution markets lecturers' experiences and elearning practices, as well as the application of e-pedagogy. Moreover, the article seeks to highlight the use of blogs as a vehicle to market these e-learning best practices, which are indicative of measuring e-learning success. Simultaneously, the article explores debates around the use of blogs as an interactional tool. Challenges encountered in the use of blogs and opportunities offered thereof are also deliberated upon the case study of the University of the Western Cape where blogging has necessitated interaction and feedback, initially about lecturers' 
impression of using e-learning at the institution to other social comments which lecturers' and students would want to post for public consumption and reaction.

\section{Showcasing the Blog as a Communication e-Tool}

The term 'blog' is a recent innovation, having derived from the combination of the two words, web and log. Blogs are akin to conversation in cyberspace where participants can share information and exchange opinions on topical issues. Blogs are virtual diaries created by individuals and stored on the internet and generally consist of text and images and can appear in a calendar type format (Trafford, 2005). Weblogs are the mavericks of the online world and two of their greatest strengths are their ability to filter and disseminate information to a widely dispersed audience, and their position outside the mainstream of mass media (Blood, 2004, p.4). The author further notes that "beholden to no one, weblogs point to, comment on, and spread information according to their own, quirky criteria". A weblog is usually a personal or non-commercial web site that uses a dated log format (usually with the most recent addition at the top of the page) and contains links to other web sites along with commentary about those sites (Blood, 2000). A weblog is updated frequently and sometimes groups links by specific subjects, such as politics, news, pop culture, or computer issues.

Blogs are located on websites which enable people to join as members and create and publish their blogs and diary entries, and can be viewed either by the general public or select groups of people, such as friends (Trafford, 2005). Blogging happens when somebody uploads information to the blog and can be created without any specific technical knowledge. Public participation in the Internet has continued to boom, aided in no small measure by the 'weblog' (or, simply, 'blog'), one of the most accessible means of online publication, a term that is rapidly entering common parlance. Blogs are authored by people from many walks of life and are of many kinds. They have also grown in intensity and sophistication from their humble origins as personal diaries. Blogs can have multiple authors linking to each other offers exciting research possibilities for exploring social learning networks and their intricate harmonies.

Today, blogs have developed the unique propensity of being much more dynamic. Some major corporations' web sites contain internal blogs, where employees can post their thoughts, ideas and more; sometimes they are public, sometimes not. Mostly, blogs are hosted on independent web sites. When using one of these, the diary keeper, or blogger, logs in and starts posting his or her thoughts in real time to the Internet. Witnesses to events can comment on breaking stories faster than the mainstream media, which usually are at least one hour from being live on the scene'. Thus, bloggers can publish reports and commentaries live on the Internet, and provide information to the world faster than traditional media, all without a publisher or editor to review or approve their work.

Despite the fact the blogs are a fairly new technological innovation, evidence of the educational benefits is accumulating and has been trumpeted in the media, even for young children (BBC News Online, 14 June 2004), though there is relatively little formal literature extolling their merits in scholarly publications, especially for higher education (HE). However, according to Williams and Jacobs (2004, p. 234) in 'Exploring the use of blogs as learning spaces in the higher education 
sector', they have concluded that based on case studies, blogs can be an effective aid to teaching and learning, pointing out that students are provided with a high level of autonomy independent of the campus, while simultaneously providing opportunity for greater interaction with peers. Ferdig and Trammell (2004) have also buttressed the same argument by maintaining that indicate that blogs support social interaction while giving students full control and ownership over their online content. A fair number of other literary works have also alluded to and shown an increasing level of positive engagement.

While much of the attention has focused on community interactions, in the UK, the government's emphasis has been on widening participation and lifelong learning that focuses on an individual's personalized learning and development, where an individual needs to reflect internally. Blogs have conveniently been employed to facilitate this process simply and effectively, especially when the object of reflection is their study; and the experiences they have will be of value not just to themselves, but to others.

Bloggers and other proponents of blogs have envisaged that at some stage the reflective blogs will need to be related to their learning environments. The Remote Authoring of Mobile Blogs for Learning Environments (RAMBLE) Project, an e-tools project, has recognized that these institutional systems are often quite remote from this 'blogosphere'. Such recognition has motivated the project to investigate how personal reflections in the HE context may be supported through mobile blogging and the provision of stepping stones into a virtual learning environment (VLE), typically core to an institution's e-learning infrastructure. The project undertook a survey among new and postgraduate students at a HE to ascertain the viability of using blogs as a communication tool among the student population and for learning purposes.

\section{Blogs within Higher Education Institutional Setting}

Blogs offer considerable potential and so it is natural to ask: How to incorporate blogs in the institutional setting, particularly with existing e-learning systems? Should the institution offer blogs to all its staff and students? Walker (2007) argues that the utilization of blogs in an education setting seeks to exemplify and discuss how students' use of weblogs can prepare them for a networked world where writing has consequences outside grades. It can be viewed as a lifelong technological expertise which can enhance students' post-education life.

Very few universities offer blogs as a general service, one of the most well known being 'Warwick Blogs', provided by Warwick University. This is a completely home-grown and heavily customized e-learning system built around blogs and integrated with local directory services, so is currently not an option for other institutions. This puts the University of the Western Cape at an advantage, given that it has experimented with blogs to facilitate debate between the E-learning Development and Support Unit (EDSU) (herein referred to as the e-learning Division) and academics and institutional leadership on their impression of the strides that e-learning has had within the institution, which is going to be the focus of this article.

Questions have risen whether other educational establishments follow Warwick's example. Although it is not easy to give a general answer, a few observations can be made. First, if blogs 
require some degree of privacy, especially within particular groups, then public hosting services are unlikely to be suitable, not least because the institution has no control - the extreme scenario being that a hosting service goes offline. Given the simplicity of blogs, it might be tempting to think that blog hosting is easy. While it may be straightforward for a small deployment, in a particular department, scaling up across an institution presents a far greater challenge.

If providing an institutional blog, one question that ought to be considered is: How many blogs are appropriate for an individual? Do people prefer to maintain just one blog in which they can store all their reflections, relating to work and study, or would they prefer to keep separate blogs depending upon the context? The judicious use of categories might enable a single blog to fulfill these roles, but there is added complexity as personal circumstances (including their learning contexts) change over time.

As blogging continues to grow in popularity, it becomes increasingly likely that schoolchildren will have blog accounts on public services before moving to further and higher education. Just as it might be the case that there need to be compelling reasons why students ought to drop their Hotmail accounts in favor of the university system, so they will need to have spelt out the value of having university blogs. As time spent at a particular university is normally only a few years, there is another issue about what happens on departure?

Trends are difficult to predict, but there will quite likely be a need to import and export the content easily in some standards-compliant way, because in contrast to the transience of e-mail, blogs provide a consolidated personal record that can be referenced in the future. Hence they need to be portable.

\section{Transformation of Communication and Marketing through Blogs and Blogging}

Communication within institutions has been a vital component that facilitates learning and information dissemination. Internal communication structures that have predominantly interaction among staff and students alike have been the e-mail and Internet facilities. However, given the dynamic nature of technology, globalization and the increasing need for faster, more efficient and effective ways of communication, the blog has, since the mid-1990s, come to dominate institutional, internal and external communication. In $\mathrm{HE}$, the blog has come to be an epi-centre of interaction between academics, among academic staff and their students, as well as among students.

Blogs and blogging have also facilitated research as both academics and students have been able to embark on edge-cutting research and information-gathering on pertinent issues. Higher education institutions (HEls), are increasingly making use of blogs to carry out surveys among fellow academics and to share information, material and knowledge of educational matters and research findings. Making use of the blog tool for an internal communication and marketing strategy also exposes the institution's practices to the global village- as the blog tool is an internet based communication tool. 


\section{Challenges and Opportunities}

Blogs have provided both opportunities and challenges for users, especially towards enhancing communication and marketing. Through blogs, one can inform others about what goes on in one part of the world. Blogs have also provided for easier access to research websites as researchers post their respective research findings on website for others to access. In addition to research findings, one can also inform readership about one's academic profile through the blog. Academics and institutions can also inform students (both current and prospective) about courses and services that are on offer.

As an example, at the University of the Western Cape, the E-Learning Division undertook to, and has been able to market its services not only to the university community but even beyond. This has facilitated interpersonal communication as clients and other users have been able to make commendations, suggestions an even recommendation on what they want to see being implemented within the E-Learning Division or to provide their assessment of the whole e-learning facility within the institution. Comments from other people can be posted as they make comments about a facility, course or service being provided. In the case of UWC, academics and institutional leadership have been able to make comments about services being provided by the E-Learning Division within the institution.

Despite the unprecedented adoption of blogs and blogging as a communication and marketing tool, there have been challenges to its introduction within and without the UWC environment, which the researchers envisage goes for other HEls across the globe. Closely associated with under-utilization of existing blogs is the fact that those who make use of the facility do not regularly up-grade their blogs, resulting in them lagging behind with information dissemination to fellow bloggers. With the dynamic nature of ICTs, upgrading of one's blog helps to keep other informed about whatever developments one needs to inform the world about. At the University of the Western Cape, just as is a common practice among some e-mail recipients, the campus community often deletes e-mail communication sent to them, some of which contain information and links to the marketing blog, thus losing valuable advice regarding the use of e-tools.

Challenges associated with ICT competencies have been realized across the political divide with hegemonic states suffering the same fate. Although the United States is commonly thought to be long on power (e.g., political, economic, cultural, technological), its citizens remain short on the competencies (i.e., knowledge, skills, and attitudes) needed to be responsible and effective members of a global community (Scorza, 2004).

Also, particular attention should be given to privacy. Most blogs, even personal diaries, are viewable by the public, but in the personal learning context, this is not always appropriate. These requirements can make it really necessary to have control over the blog server in-house. Thus, access to the blogs can be set up so that there is only one owner per blog and the only others who could read and respond to the blogs are their peers plus the blog project supervisor and other team members. Pebble and other blog hosting services provide some means of restricting access, but this generally assumes that users are accessing the service directly through the Web interface and not via a third-party system. 


\section{Conclusion}

The Information Age has presented some of the most evident benefits of all time, especially given the propensity and agility with which people can now communicate, interact and even share notes on topical economic, social and political developments across the globe. The ability to some of the social utilities to employ audio and visual presentations has further made the use of them not only a necessity but more interesting and a source of joy. In short, most of the social utilities have been able to lived the world and lives of users. On the education side, the unprecedented number of students seeking to further their academic and professional skills could not have come at the right time. It is unimaginable how institutions would have handled the large number of tertiary students in the absence of ICTs. In addition, balancing work and study would not have taken off from the ground for most distance education and part-time student without the invaluable utilization of the internet. The private sector has also benefited from the products of higher education institutions whose skills have been able to service industry for economic growth and development. Should one dare to cite any disadvantages brought about by the introduction of technology, then such deliberations would not outweigh advantages brought about by ICTs in education, communication and marketing as well as for employment as social utilities.

\section{References}

Allen et al. (2003). Comparing student satisfaction with distance education to traditional classrooms in higher education: A meta-analysis. The American Journal of Distance Education, 16 (2), 83-97.

Bates, A. (2005). Technology, e-learning and distance education. London: Routledge.

Bates, A. \& Poole, G. (2003). Effective teaching with technology in higher education. San Francisco, CA: Jossey-Bass/John Wiley.

BBC News online (14 June 2004). The seven-year-old bloggers. http://news.bbc.co.uk/2/hi/uk_news/magazine/3804773.stm

Blood, R. (2000). Weblogs: A history and perspective, Rebecca's Pocket. Available at: www.rebeccablood.net/essays/weblog_history.html, 7/9/2000 [Accessed 29 November 2009].

Blood, R (2004). Weblog Ethics. The Weblog handbook: Practical advice on creating and maintaining your blog (pp. 114-121). Cambridge: Perseus.

Bullen, M. (1998). Participation and critical thinking in online university distance education. Journal of Distance Education, 13(2), 1-32.

The European E-Learning Summit Task Force. (2001). The European eLearning Summit. Available at: http://ec.europa.eu/education/archieve/elearning/summit.pdf

Ferdig, R. E. \& Trammell K. D. (2004). Content delivery in the Blogosphere. T.H.E. Journal Online, Retrieved 04 February 2004 from http://www.thejournal.com/magazine/vault/ articleprintversion.cfm?aid $=4677$ 
Frankel, J. (2000). Globalization of the economy. Available at: citeseerx.ist.psu.edu/viewdoc/ download?doi=10.1.1.32.313

Harris, R.G. (1993). Globalization, trade, and income. Canadian Journal of Economics, 4, 755-776.

International Monetary Fund (IMF). (1997). Annual report of the executive board for the financial year ended April 30, 1997. Washington, DC: The author. Available at: http://www.imf.org/ external/pubs/ft/ar/97/pdf/file01.pdf

Marshall, S, Kinuthia, W., \& Taylor, W. (Eds). (2009). Bridging the knowledge divide: Educational Technology for Development. The University of the West Indies.

Rodrik, D. (1997). Globalization, social conflict, and economic growth. Available at: http://atecex.uexternado.edu.co/eco2fin/Lecturas/(Rodrik)\%20Globalizacion\%20conflicto\% 20social\%20y\%20crecimiento.pdf

Scorza, J. (2004). Teaching global citizenship: The paradox of competency and power. Paper presented at the annual meeting of the American Political Science Association. Hilton Chicago and the Palmer House Hilton, Chicago, IL: Sep 02, 2004. Retrieved 2 December 2009 from http://www.allacademic.com/meta/p59499_index.html

Trafford, P. (2005). Remote authoring of mobile blogs for learning environments: JISC DEL E-Tools Project. Available at: http://www.jisc.ac.uk/deletramble.html

Tynan, B. \& Colbran, S. (2006). Podcasting, student learning and expectations. Proceedings of the 23 Annual Ascilite Conference: Who's learning? Whose technology? (pp. 825-832). Sydney: Australia. The University of Syndney.

Walker, J. (2007). Weblog: Learning in public on the horizon. Available at: http://www.emeraldinsight.com/Insight/ViewContentServlet;jsessionid=5C9C847EF05D1DC C190B3BA87264DF6F?contentType=Article\&Filename=Published/EmeraldFullTextArticle/Ar ticles/2740130207.html]

Wells, G. J. (2004). The issue of globalization. In R. E. Westerfield (Ed.), Current issues in globalization (pp. 179-202). Hauppauge, NY: Nova.

Wikipedia (2009). Information age. Available at: http://en.wikipedia.org/wiki/Information_Age.

Williams, J.B., \& Jacobs, J. (2004). Exploring the use of blogs as learning spaces in the higher education sector. Australasian Journal of Educational Technology, 20(2), 232-247. Available at: http://ascilite.org.au/ajet/ajet20/williams.html

Wong, M. (2003). Panel 2: Global trends of e-learning for quality education: A school perspective. Available at: http://www.hkwebsym.org.hk/2003/panel2.htm

Zhao, Y., Lei, J., Yan, B., \& Tan, S. (2004). What makes the difference? A practical analysis of research on the effectiveness of distance education. Available at: http://ott.educ.msu.edu/ literature/report.pdf.

Correspondence: Jephias Mapuva, Researcher, E-Learning Division, University of the Western 